\title{
Non-Hodgkin Lymphoma Relapse Presenting as Isolated Neurolymphomatosis of the Brachial Plexus - A Case Report
}

\begin{abstract}
Neurolymphomatosis is a rare manifestation of non-Hodgkin's lymphoma (NHL) and is characterized by infiltration of the nerves by neoplastic lymphoid cells and is seen in up to $0.2 \%$ of all NHL cases. Diagnosing this syndrome is quite a challenge to the hematologists given the vague symptoms and signs and the low incidence. Newer imaging modalities such as positron emission tomographycomputed tomography and magnetic resonance imaging have enabled early diagnosis with a sensitivity reaching up to $100 \%$. Despite a variety of therapies reported in the literature for the treatment, the prognosis is very poor. We report a 46-year-old male diagnosed to have NHL-diffuse large B-cell lymphoma and treated with rituximab, cyclophosphamide, vincristine, and prednisolone (R-CHOP) therapy who presented with left brachial plexus neurolymphomatosis as the initial feature of disease relapse.
\end{abstract}

Keywords: Brachial plexus, chemotherapy, neurolymphomatosis, non-Hodgkin's lymphoma

\section{Introduction}

Neurolymphomatosis (NL) is a rare condition that occurs due to lymphomatous or leukemic involvement of the central or peripheral nervous system. ${ }^{[1]}$ Although the condition may occur in any leukemia or lymphomas, non-Hodgkin's Lymphoma (NHL) is the most frequent cause with a reported incidence of $0.2 \%{ }^{[2]}$ Nervous system involvement in NHL can be due to (i) direct compression of the nerves by adjacent lymph nodes, (ii) immune-mediated paraneoplastic neuropathy, (iii) chemotherapy or radiation induced neurotoxicity, (iv) infiltration nutritional, and (v) direct lymphomatous of the nerve (NL). ${ }^{[2]}$ It is important to differentiate NL from other causes of nervous system involvement in a setting of lymphoma as there is a considerable difference in the management of each etiology. We report a 46-year-old male diagnosed to have NHL-diffuse large B-cell lymphoma (NHL-DLBCL) subtype and treated with rituximab, cyclophosphamide, vincristine, and prednisolone (R-CHOP every 21-day cycle) therapy who presented with left brachial plexus NL as the initial feature of disease relapse. The challenges

This is an open access journal, and articles are distributed under the terms of the Creative Commons Attribution-NonCommercial-ShareAlike 4.0 License, which allows others to remix, tweak, and build upon the work non-commercially, as long as appropriate credit is given and the new creations are licensed under the identical terms.

For reprints contact: WKHLRPMedknow_reprints@wolterskluwer.com in diagnosis and management of NL are discussed in this case report.

\section{Case Report}

A 46-year-old male presented with left shoulder pain, weakness, and inability to move the left upper limb for the past 6 weeks. He also complained of tingling sensation in the fingers of the left hand. Eighteen months previously, he had been diagnosed with Stage IV diffuse large B-cell NHL (Lugano criteria) with International Prognostic Index score of 4/5. ${ }^{[3]} \mathrm{He}$ had been admitted with complaints of low back pain, dyspnea on exertion, and multiple swellings in the neck for the past 1-month duration. The physical examination had revealed pallor, multiple enlarged lymph nodes in the right cervical and left supraclavicular regions, a large palpable irregular mass per abdomen, and a right pleural effusion. The neurological evaluation was normal. Fluorodeoxyglucose (FDG) positron emission tomography-computed tomography (PET-CT) showed multiple FDG-avid lymph nodes (maximum standardized uptake value [SUVmax] range: 7.6-16.7) in the right cervical, both supraclavicular and mediastinal regions. FDG-avid (SUVmax of 14.87) soft-tissue lesion was seen in the right

\footnotetext{
How to cite this article: Parashar $Y$, Hasan $F$, Bishnu A, Kashyap R. Non-Hodgkin lymphoma relapse presenting as isolated neurolymphomatosis of the brachial plexus - A case report. Indian J Med Paediatr Oncol 2020;41:741-4.
}

Yatendra Parashar, Faheema Hasan, Arijit Bishnu, Rajesh Kashyap

Department of Hematology, Sanjay Gandhi Postgraduate Institute of Medical Sciences, Lucknow, Uttar Pradesh, India

Submitted: 08-Oct-2019 Revised: 10-Nov-2019

Accepted: 03-Jan-2020

Published: 29-Oct-2020

Address for correspondence:

Dr. Rajesh Kashyap,

Department of Hematology, Sanjay Gandhi Postgraduate Institute of Medical Sciences, Lucknow - 226014 ,

Uttar Pradesh, India.

E-mail: rajkashyapmd@ yahoo.co.in

Access this article online Website: www.ijmpo.org DOI: 10.4103/ijmpo.ijmpo_207_19 Quick Response Code:

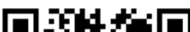

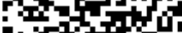

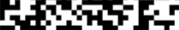
priszife arisgd. 
anterior chest wall with intrathoracic extension, measuring $6.0 \mathrm{~cm} \times 6.5 \mathrm{~cm}$. A right pleural effusion with passive lung collapse was present. A conglomerate mass of multiple FDG-avid (SUVmax of 20.15) retroperitoneal lymph nodes was also present. Normal uptake was seen in the spleen, liver, and other organs. Histopathology of the lymph node showed diffuse infiltration by sheets of atypical lymphoid cells which were medium sized with high N: $\mathrm{C}$ ratio, diffuse chromatin, conspicuous nucleoli, and scant cytoplasm. On immunohistochemistry (IHC), the atypical cells were positive for leukocyte common antigen, CD20, and PAX5 and negative for cytokeratin, synaptophysin, chromogranin, terminal deoxyribonucleotide transferase, CD30, and ALK. Ki-67 labeling index was 75\%. IHC for differentiating GC versus non-GC and molecular genetic tests for BCL2/MYC status was not performed. The cerebrospinal fluid (CSF) examination was negative for malignant cells. He has treated with systemic chemotherapy RCHOP (total six cycles) and intrathecal methotrexate. The patient had a complete response (CR, Lugano criteria). ${ }^{[3]}$ He was disease free for the past 12 months.

Physical examination revealed that there was wasting of muscles of the shoulder girdle, arm, forearm, and hand of the left upper extremity. The motor strength of proximal muscles was $2 / 5$ and intrinsic muscles of the hand were $<25 \%$, and deep tendon reflexes were absent. Sensory testing was normal except for the presence of numbness and tingling sensation on the left finger tips. Laboratory investigations revealed normal hemogram and biochemical tests for liver and renal functions. A nerve conduction study of the upper limbs demonstrated marked motor and sensory axonal loss in the left upper limb nerves suggestive of left brachial plexus plexopathy. Magnetic resonance imaging (MRI) revealed diffuse thickening of the roots, trunks, cords, and divisions of the left brachial plexus which was hyperintense on STIR with homogeneous post contrast enhancement [Figure 1]. PET-CT revealed FDG-avid uptake (SUVmax of 15.6.) in the left brachial plexus suggestive of lymphomatous involvement [Figure 2]. The CSF cytology was negative for the presence of malignant cells. Bone marrow examination showed normocellular marrow with normal trilineage hematopoiesis. A diagnosis of NL left brachial plexus secondary to NHL relapse was made. The patient was planned to be treated with systemic salvage chemotherapy, rituximab plus dexamethasone, cytosine arabinoside, and cisplatin (R-DHAP), and high-dose methotrexate (HD-MTX, $3.5 \mathrm{~g} / \mathrm{m}^{2} \mathrm{IV}$ ) with every alternate cycles of R-DHAP followed by autologous stem cell transplant. Adjuvant radiation therapy (35 Gy in 18 fractionated doses) was given to the affected site. After two cycles of chemotherapy, the patient showed neurological improvement and there was a marked improvement in his upper limb weakness (motor power $4 / 5$ at the shoulder and elbow joints and hand grip $75 \%$ of normal). However, post the third cycle of chemotherapy, he developed febrile neutropenia with sepsis and died.

\section{Discussion}

$\mathrm{NL}$ is a unique condition that occurs due to direct infiltration of the endoneurium of the nerve by neoplastic lymphocytes. $^{[1]}$ It has more frequently been observed in patients with NHL. DLBCL is the most common histological subtype, followed by follicular lymphoma and very rarely T-cell lymphomas. NL may be the primary presentation of NHL or may present as disease progression or relapses. ${ }^{[2,4]}$

The clinical manifestations of NL depend on the cranial and peripheral nerves involved. Baehring et al. ${ }^{[2]}$ have described four patterns of clinical presentation: (i) painful involvement of nerves and roots, (ii) cranial neuropathy with or without pain, (iii) painless involvement of peripheral nerves, and (iv) painful or painless involvement of single peripheral nerve. Peripheral nervous system involvement is usually in the form of mononeuropathy and rarely polyneuropathy, isolated sciatic nerve, median nerve, and ulnar nerve involvements have also been reported. ${ }^{[4-10]}$

Brachial plexus involvement due to NL has been documented with clinical presentation ranging from focal distal mononeuropathy to multifocal brachial plexopathy. ${ }^{[6-10]}$ Kamiya-Matsuoka et al., in a case series of six patients with NL, found that four of them had NHL-DLBCL. Brachial plexus involvement was seen in three patients, and they had presented with unilateral upper limb weakness and hyporeflexia. ${ }^{[8]}$ The fourth patient had radiculopathy of the left $\mathrm{T} 1$ and right $\mathrm{L} 5$ spinal nerves. Choi et al. have reported two cases of NL of the brachial plexus and both were DLBCL histological subtype. One patient developed right arm weakness and pain during remission of the disease following eight cycles of R-CHOP chemotherapy. The second patient, a 50-year-old female, presented with right upper limb pain and weakness during the course of therapy for primary central nervous system (CNS) lymphoma. ${ }^{[9]}$ Bourque et al. have also reported three cases with NL of the brachial plexus: one patient had cutaneous B-cell NHL and three patients had NHL-DLBCL [Table 1]. ${ }^{[10]}$ Systemic chemotherapy (CHOP/R-CHOP) with intrathecal methotrexate and local radiotherapy (35 to 40 Gy in 15 to 18 fractionated doses) have been the main modalities of treatment in these patients. Intravenous immunoglobulins and plasma exchange have also been used (8.10). NHL patients who achieved disease remission showed neurological improvement and have had better overall survival (OS) compared to those patients who had disease progression or relapse during therapy. These patients showed transient or no improvement in their neuropathy and had a poorer OS [Table 1].

NL can be diagnosed by radiologically MRI and PET-CT. A MRI study in NL thickening of the involved peripheral 
nerves or roots with isointensity to muscle on T1 sequence, hyperintensity on T2 or STIR signaling, and significant focal diffuse gadolinium enhancement. ${ }^{[4,11]}$ The sensitivity of MRI ranges between $70 \%$ and $80 \%{ }^{[2,3]}$ PET-CT appears to be the single most sensitive imaging tool in identifying

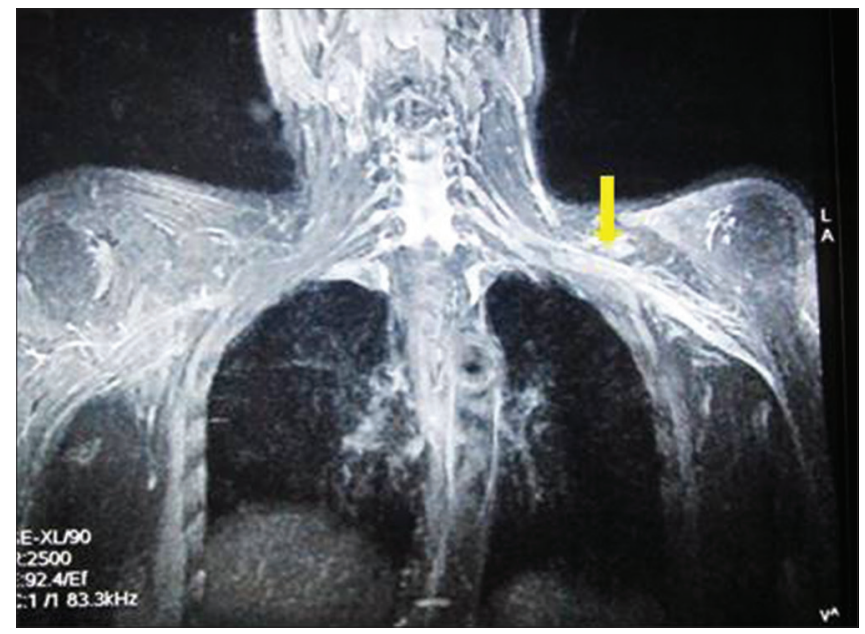

Figure 1: Magnetic resonance imaging of the thorax shows diffuse thickening of the roots, trunks, cords, and divisions of the left brachial plexus (arrow mark), which is hyperintense on T2 and STIR sequence
NL with a sensitivity reaching up to $100 \%$. The affected nerve shows enhanced FDG uptake due to increased metabolic activity. PET-CT invariably confirms NL in previously diagnosed and treated cases of NHL. ${ }^{[4,5]}$ When both the imaging modalities have combined, the diagnosis

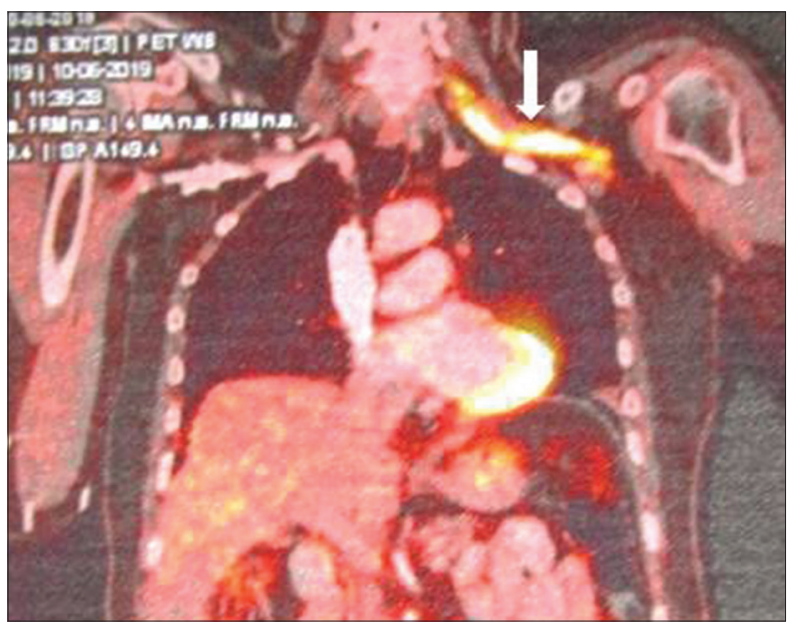

Figure 2: Positron emission tomography-computed tomography shows increase fluorodeoxyglucose avidity (maximum standardized uptake value of 15.67) of the left brachial plexus (arrow mark)

\begin{tabular}{|c|c|c|c|c|c|}
\hline Author (reference) & Age/sex & Disease & $\begin{array}{l}\text { Neurological } \\
\text { presentation }\end{array}$ & Treatment & Outcome \\
\hline \multicolumn{6}{|l|}{$\begin{array}{l}\text { Kamiya-Matsuoka } \\
\text { et al. } .^{[8]}\end{array}$} \\
\hline Patient 1 & 61 male & NHL-DLBCL & $\begin{array}{l}\text { Right brachial } \\
\text { plexopathy }\end{array}$ & $\begin{array}{l}\text { Systemic and intrathecal } \\
\text { chemotherapy }\end{array}$ & $\begin{array}{l}\text { Disease progression, neurologica } \\
\text { residual deficit. OS: } 12.3 \text { months }\end{array}$ \\
\hline Patient 2 & 76 male & NHL-DLBCL & $\begin{array}{l}\text { Right brachial and } \\
\text { lumbar plexopathy }\end{array}$ & $\begin{array}{l}\text { Systemic and intrathecal } \\
\text { chemotherapy, IVIG }\end{array}$ & $\begin{array}{l}\text { Disease progression, initial } \\
\text { neurological improvement OS: } \\
12.4 \text { months }\end{array}$ \\
\hline Patient 3 & 55 male & NHL-DLBCL & $\begin{array}{l}\text { Left } \mathrm{T} 1 \text { and right } \mathrm{L} 5 \\
\text { radiculopathy }\end{array}$ & $\begin{array}{l}\text { Systemic and intrathecal } \\
\text { chemotherapy, IVIG, PLEX }\end{array}$ & $\begin{array}{l}\text { Disease remission, mild } \\
\text { neurological improvement OS } \\
30.6 \text { months }\end{array}$ \\
\hline Patient 4 & 61 female & NHL-DLBCL & $\begin{array}{l}\text { Right brachial } \\
\text { plexopathy }\end{array}$ & Systemic chemotherapy & $\begin{array}{l}\text { Disease remission, neurological } \\
\text { improvement OS: } 30.8 \text { months }\end{array}$ \\
\hline \multicolumn{6}{|l|}{ Choi et al..$^{[9]}$} \\
\hline Patient 1 & 60 male & NHL-DLBCL & $\begin{array}{l}\text { Right brachial } \\
\text { plexopathy }\end{array}$ & $\begin{array}{l}\text { Systemic and intrathecal } \\
\text { chemotherapy }\end{array}$ & $\begin{array}{l}\text { Disease progression, neurologica } \\
\text { improvement OS: } 3.0 \text { months }\end{array}$ \\
\hline Patient 2 & 50 female & $\begin{array}{l}\text { Primary CNS } \\
\text { Lymphoma }\end{array}$ & $\begin{array}{l}\text { Right brachial } \\
\text { plexopathy }\end{array}$ & $\begin{array}{l}\text { Radiotherapy ( } 35 \text { Gy) } \\
\text { Radiotherapy ( } 35 \text { Gy) }\end{array}$ & $\begin{array}{l}\text { Disease progression, neurologica } \\
\text { improvement OS: } 8.0 \text { months }\end{array}$ \\
\hline \multicolumn{6}{|l|}{ Bourque et al..$^{[10]}$} \\
\hline Patient 1 & 78 female & $\begin{array}{l}\text { B-cell NHL } \\
\text { recurrence }\end{array}$ & Right ulnar N palsy & $\begin{array}{l}\text { Systemic chemotherapy and } \\
\text { radiotherapy ( } 40 \text { Gy) }\end{array}$ & $\begin{array}{l}\text { Disease progression, no } \\
\text { neurological improvement OS } \\
24.0 \text { months }\end{array}$ \\
\hline Patient 2 & 44 male & NHL-DLBCL & $\begin{array}{l}\text { Bilateral brachial } \\
\text { plexopathy }\end{array}$ & $\begin{array}{l}\text { Systemic chemotherapy and } \\
\text { IVIG }\end{array}$ & $\begin{array}{l}\text { Disease response, transient } \\
\text { neurological improvement OS: } \\
\text { NR }\end{array}$ \\
\hline Patient 3 & 67 male & $\begin{array}{l}\text { NHL-DLBCL } \\
\text { Relapse }\end{array}$ & $\begin{array}{l}\text { Left brachial } \\
\text { plexopathy }\end{array}$ & $\begin{array}{l}\text { Systemic chemotherapy, } \\
\text { radiotherapy ( } 35 \mathrm{~Gy})\end{array}$ & $\begin{array}{l}\text { Disease progression, no } \\
\text { neurological improvement } \\
\text { palliative care. OS: NR }\end{array}$ \\
\hline
\end{tabular}

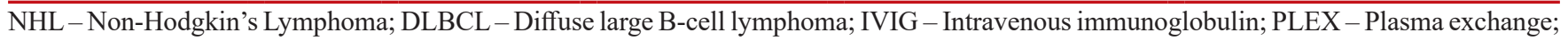
OS - Overall survival; NR - Not recorded 
of NL is more or less certain, and nerve biopsy may not be required. Treatment protocols for NL have not standardized because of the rarity of this condition.

In the majority of published articles, systemic chemotherapy R-CHOP with added HD-MTX has been the treatment of choice. The latter penetrates the blood-brain barrier and reduces the risk of the CNS disease relapse. ${ }^{[4,12]}$ Radiotherapy has a role limited to reducing neuropathic pain and local disease control. ${ }^{[12]}$ The prognosis of patients with NL is extremely poor with a 36-month survival of only $24 \%$ and median survival of 10 months. ${ }^{[4]}$ The poor survival is probably due to the fact that NL is more frequently seen in more aggressive disease and chemotherapy resistance, both of which are associated with early relapses. ${ }^{[4]}$

Our patient presented with left brachial plexopathy 1 year after successful treatment of NHL with R-CHOP therapy as a sole manifestation of disease relapse. He had no evidence of systemic relapse. He has shown neurological improvement after two cycles of R-DHAP salvage chemotherapy and HD-MTX but died due to postchemotherapy neutropenic septicemia after the third cycle. In conclusion, we would like to state that NL must be suspected in any NHL patients presenting with cranial nerve or peripheral nerve involvement as the diagnosis is often missed because it mimics nonneoplastic and paraneoplastic neuropathies. Integrating clinical, laboratory results and imaging findings helps in confirming the diagnosis and starting early treatment.

\section{Declaration of patient consent}

The authors certify that they have obtained all appropriate patient consent forms. In the form the patient(s) has/have given his/her/their consent for his/her/their images and other clinical information to be reported in the journal. The patients understand that their names and initials will not be published and due efforts will be made to conceal their identity, but anonymity cannot be guaranteed.

Financial support and sponsorship

Nil.

\section{Conflicts of interest}

There are no conflicts of interest.

\section{References}

1. Hughes RA, Britton T, Richards M. Effects of lymphoma on the peripheral nervous system. J R Soc Med 1994;87:526-30.

2. Baehring JM, Damek D, Martin EC, Betensky RA, Hochberg FH. Neurolymphomatosis. Neuro Oncol 2003;5:104-15.

3. Cheson BD, Fisher RI, Barrington SF, Cavalli F, Schwartz LH, Zucca E, et al. Recommendations for initial evaluation, staging, and response assessment of Hodgkin and non-Hodgkin lymphoma: The Lugano classification. J Clin Oncol 2014;32:3059-68.

4. Grisariu S, Avni B, Batchelor TT, van den Bent MJ, Bokstein F, Schiff D, et al. Neurolymphomatosis: An International Primary CNS Lymphoma Collaborative Group report. Blood 2010;115:5005-11.

5. Sideras PA, Matthews J, Sakib SM, Ofikwu F, Spektor V. Neurolymphomatosis of the peripheral nervous system: A case report and review of the literature. Clin Imaging 2016;40:1253-6.

6. Swarnkar A, Fukui MB, Fink DJ, Rao GR. MR imaging of brachial plexopathy in neurolymphomatosis. AJR Am J Roentgenol 1997;169:1189-90.

7. Liang R, Kay R, Maisey MN. Brachial plexus infiltration by non-Hodgkin's lymphoma. Br J Radiol 1985;58:1125-7.

8. Kamiya-Matsuoka C, Shroff S, Gildersleeve K, Hormozdi B, Manning JT, Woodman KH. Neurolymphomatosis: A case series of clinical manifestations, treatments, and outcomes. J Neurol Sci 2014;343:144-8.

9. Choi YJ, Shin JA, Kim YH, Cha SJ, Cho JY, Kang SH, et al. Neurolymphomatosis of brachial plexus in a patient with non-Hodgkin's Lymphoma. Case Rep Oncol Med 2013;2013:492329. Doi 10.1155/2013/492329.

10. Bourque PR, Warman Chardon J, Bryanton M, Toupin M, Burns BF, Torres C. Neurolymphomatosis of the brachial plexus and its branches: Case series and literature review. Can J Neurol Sci 2018;45:137-43.

11. Thawait SK, Chaudhry V, Thawait GK, Wang KC, Belzberg A, Carrino JA, et al. High-resolution MR neurography of diffuse peripheral nerve lesions. AJNR Am J Neuroradiol 2011;32:1365-72.

12. Lagarde $\mathrm{S}$, Tabouret $\mathrm{E}$, Matta $\mathrm{M}$, Franques $\mathrm{J}$, Attarian $\mathrm{S}$, Pouget $\mathrm{J}$, et al. Primary neurolymphomatosis diagnosis and treatment: A retrospective study. J Neurol Sci 2014;342:178-81. 